\title{
Obstacles to contraceptive use in Pakistan: A study in Punjab
}

\author{
John B. Casterline \\ Population Council \\ Zeba Sathar \\ Population Council \\ Minhaj ul Haque \\ Population Council
}

Follow this and additional works at: https://knowledgecommons.popcouncil.org/departments_sbsr-pgy

Part of the Demography, Population, and Ecology Commons, Family, Life Course, and Society Commons, and the International Public Health Commons How does access to this work benefit you? Let us know!

\section{Recommended Citation}

Casterline, John B., Zeba Sathar, and Minhaj ul Haque. 2001. "Obstacles to contraceptive use in Pakistan: A study in Punjab," Policy Research Division Working Paper no. 145. New York: Population Council. Version of record: https://doi.org/10.1111/j.1728-4465.2001.00095.x 


\section{O bstacles to Contraceptive Use in Pakistan: A Study in Punjab}

John B. Casterline

Zeba A. Sathar

Minhaj ul Haque

2001 No. 145 


\title{
Obstacles to Contraceptive Use in Pakistan: A Study in Punjab
}

\author{
John B. Casterline \\ Zeba A. Sathar \\ Minhaj ul Haque
}

John B. Casterline is Senior Associate, Policy Research Division, Population Council, New York. Zeba A. Sathar is Deputy Representative and Program Associate and Minhaj ul Haque is Senior Program Officer, Population Council, Islamabad, Pakistan.

This research was supported by the Rockefeller Foundation through the award "Unmet need for family planning: its nature and causes" and by the United Nations Population Fund through the award "Learning about men." An earlier version of this paper was presented at the annual meeting of the Population Association of America, New York, 25-27 March 1999. The authors are grateful to Sajeda Amin, John Bongaarts, James Shelton, and Amy Tsui for helpful comments on earlier versions. 


\begin{abstract}
The principal aim of this study is to assess the strength in Pakistan of a set of hypothesized obstacles to practicing contraception. Our concern is those factors that prevent women from translating a desire to avoid becoming pregnant into contraceptive practice, a common predicament in Pakistan in recent decades. We analyze survey data collected in Punjab province in 1996 that contain unusually detailed measurement of various perceived costs of practicing contraception, as well as focused measurement of fertility motivation. The framework guiding the research specifies six major obstacles to contraceptive use: the strength of motivation to avoid pregnancy, awareness and knowledge of contraception, the social and cultural acceptability of contraception, perceptions of the husband's preferences and attitudes, health concerns, and perceived access to services. For each of these, the survey data provide a block of measured indicators. Net effects of each obstacle are estimated through structural equation modeling of the intention to practice contraception in the near future (the two years subsequent to the survey) in which the six obstacles are treated as latent variables. The estimates indicate that the two principal obstacles to using a contraceptive are the woman's perception that such behavior would conflict with her husband's views (that is, his fertility preferences and his attitudes toward family planning) and her perception of the social or cultural unacceptability of contraception. Of lesser importance but also significant is the woman's awareness and knowledge of contraception. The other three obstacles do not show statistically significant effects. The results confirm the value of taking contraceptive costs seriously, and, in particular, of attempting to measure these costs in empirical research on family planning. Punjabi women confront many obstacles to adopting and continuing to practice contraception, and policies and programs that overcome these obstacles should be developed.
\end{abstract}

This material may not be reproduced without written permission from the authors. 
In 1965, motivated by concerns about rapid population growth, Pakistan was among the first Asian countries to enunciate a national population policy (Rukanuddin and Hardee-Cleaveland 1992; Rosen and Conley 1996). Soon thereafter, the National Impact Survey of 1968-69 appeared to demonstrate that this national policy and the programmatic interventions that flowed from it had considerable potential for success: The survey revealed that a large proportion of women of reproductive age expressed a desire to terminate childbearing but were not using any method of contraception (Sirageldin et al. 1976). This discrepancy between stated fertility preferences and reported contraceptive behavior was interpreted as indicative of latent demand for contraception. Indeed, surveys carried out in many countries in Africa, Asia, and Latin America in the period since 1975 have shown that a discrepancy between fertility preferences and contraceptive behavior, commonly labeled "unmet need for family planning," characterizes a sizable fraction (typically between 15 percent and 25 percent) of women of reproductive age in pretransitional and transitional societies (Westoff and Bankole 2000).

What is remarkable about Pakistan is not the existence of this preference-use gap but rather its persistence at relatively high levels for decades without any significant change in contraceptive prevalence (and, accordingly, in period fertility rates, which in the three decades leading up to the 1990s probably exceeded six births per woman [Sathar and Casterline 1998]). National surveys carried out in 1974-75 (PFS[WFS]), 1984, and 1990-91 (PDHS) documented roughly the same prevalence of unmet need-around one-fourth to one-third of currently married women (Westoff and Bankole 2000) - together with essentially unchanging contraceptive prevalence (less than 12 percent). Another indication of the persistence of a gap between reproductive aspirations and reproductive outcomes is the relatively stable 1.5-2.0-child difference between ideal family size and the total fertility rate (TFR) over this same two-decade period. Identification of another country in which fertility desires and fertility behavior remained stable and in sharp contradiction for such a lengthy period would be difficult. Some inferences might be drawn from this persistent gap: that the social and cultural obstacles to contraceptive use are unusually powerful and deep-seated in Pakistani society, and that the provision of family planning services has been especially poorly designed and implemented in Pakistan (Rosen and Conley 1996). 
Contraceptive prevalence began to increase in the 1990s, rising from 12 percent as reported in the 1990-91 PDHS (NIPS and IRD/Macro International 1992) to 24 percent in the 1996-97 Pakistan Fertility and Family Planning Survey (NIPS/LSHTM 1998), a rise of roughly 2 percentage points per annum. Nevertheless, unmet need for family planning remains at relatively high levels by international standards (Westoff and Bankole 2000). Similarly, fertility rates, although apparently on the decline, are also high in relation to other South Asian nations and in relation to conventional measures of socioeconomic development, such as income and urbanization (see Tsui 1996).

Our goal in this study is to determine which factors stymie the translation of women's desires to avoid pregnancy into contraceptive practice in Pakistan in the late 1990s. To this end, we make use of empirical data collected in Punjab province in 1996 that contain many measures of the various hypothesized obstacles to contraceptive use, measures that are largely unavailable in other recent national surveys.

\section{CONCEPTUAL FRAMEWORK}

In tackling the question of why some Pakistani women practice contraception and others do not, we begin with the Easterlin Synthesis Framework (Easterlin 1975; Hermalin 1983), in which fertility regulation is a function of two classes of factors, the motivation to avoid pregnancy and the costs of fertility regulation. Costs are broadly defined to include not simply the time and financial resources required to acquire contraceptive supplies and services but also the social, psychic, cultural, and health costs (real and perceived) that accompany adoption and continued use of contraceptives. The focus here is this constellation of factors, which until recently were relatively neglected in research on family planning (Bongaarts and Bruce 1995). Although substantial declines in desired family size are clearly a prerequisite for fertility to fall to replacement level in Pakistan (Shah and Cleland 1993; Sathar and Casterline 1998), the central question during the past three decades has been why a large fraction of Pakistani women express a desire to avoid pregnancy but do not practice family planning. This question about the causes of unmet need for contraception presumes the existence of a motivation to avoid pregnancy that is not translated into behavior because of the existence of one or more obstacles to contraceptive use. 
To identify the major obstacles to family planning in Pakistan, we draw both on previous empirical research in Pakistan and on exploratory qualitative interviews that we conducted at an early stage in our work. We summarize the main findings from the existing research literature and discuss conclusions from analysis of the qualitative interviews.

A series of studies carried out during the past three decades have sought to explain the discrepancy in Pakistan between fertility preferences and contraceptive practice. Among the more important of these studies, Sirageldin et al. (1976), in an analysis of the National Impact Survey of 1968-69 that relies mainly on indirect evidence, attribute the high latent demand for contraception to cultural and social constraints and to inadequate family planning services. Drawing on more direct indicators available in the Pakistan Fertility Survey of 1974-75, Shah and Shah (1984) conclude that the primary reasons for nonuse of contraceptives among apparently motivated women are the perception that family planning is unacceptable on religious grounds, fear of contraceptives' side effects on health, opposition from husbands, and, finally, the limited availability of family planning services. Mahmood (1992) analyzes the 1979-80 Population, Labour Force and Migration (PLM) survey and infers from the pattern of effects of socioeconomic and demographic variables that psychological and sociocultural factors, in particular strong religious and social values, are the key to understanding unmet need. In a subsequent analysis of the 1990-91 Pakistan Demographic and Health Survey, Mahmood and Ringheim (1996) conclude that the primary determinants of contraceptive use (not conditional on a desire to avoid pregnancy) are knowledge of a supply source, husband-wife communication, and religious attitudes. Hashmi et al. (1993) conducted a follow-up study of nonusers in Punjab in the 1990-91 DHS and identify fear of side effects on health, religious concerns, lack of knowledge of a source of contraceptive supplies, and husbands' opposition as the chief barriers to use. Other analyses have focused on the national family planning program and invariably criticize it harshly for poor management and the low quality of the services offered to the majority of its clients (Robinson et al. 1981; Mahmood 1992; Rukanuddin and Hardee-Cleaveland 1992).

Although previous research in Pakistan yields what would seem to be a relatively comprehensive listing of possible obstacles to contraceptive use, we began this research with our own exploratory qualitative interviews to assure ourselves that important ob- 
stacles had not been overlooked and to develop a better understanding of the nature of these obstacles for the purpose of improving the formulation of survey questionnaire items. Eight focus-group discussions and 34 in-depth interviews were conducted with men and women in eight locales in north, central, and southern Punjab. In all, more than 100 individuals were asked their views about what factors account for the failure of women or couples to translate their reproductive preferences into contraceptive practice. In giving both the discussions and the interviews careful readings, we find the interviews to be more revealing of reasons for unmet need. What emerges most clearly from the qualitative interviews with women is the extent to which users and nonusers are polarized in their fear of side effects and in their perceptions of husbands' disapproval of contraception. Men, in contrast, invoke a more diverse set of reasons for nonuse, ranging from religious concerns to fear of social ostracism, concern about financial costs, and fear of side effects. A further finding from these interviews is that men cite their wives' disapproval as a reason for not implementing reproductive intentions less frequently than women cite their husbands' disapproval. This finding is entirely consistent with the prevailing view in Pakistani society that decisionmaking about reproductive matters resides primarily with the husband. Interestingly, the qualitative interviews indicate clearly that deliberate fertility regulation, through modern family planning and other means, is becoming much more acceptable to both women and men on religious and social grounds. Old mores on this point are weakening. A further change that respondents perceive is a withdrawal of elders and in-laws from the decisionmaking process, with the result that decisions about contraception are increasingly the exclusive province of the wife and husband. In our survey analysis we examine some of the themes that emerged from the qualitative interviews.

On the basis of this exploratory qualitative research and of a reading of previous research on Pakistan, we arrived at a framework for identifying obstacles to contraceptive use in Pakistan. This framework influenced the design of the 1996 survey data collection in Punjab, and it structures the analysis that follows. We posit that, among those wishing to avoid pregnancy, the decision to practice contraception is determined by the following: the strength of the motivation to avoid pregnancy; knowledge about contraception (the existence of methods and how they work); the costs of practicing contraception, specifically perceptions of the social, cultural, and religious acceptability of contraception; percep- 
tions of the husband's opposition to family planning; health concerns about contraception; and inadequate access to family planning services of acceptable quality.

The analytical value of this breakdown is twofold. First, it gives structure to the analysis. Equally important, it provides an organizing framework for assessment of the policy and programmatic implications of the results. From this standpoint, singling out poor access to family planning services is clearly important. The scope for programmatic initiatives that weaken barriers to contraceptive use surely extends beyond improving access, however. Knowledge of contraception might be improved through appropriate information, education, and communication efforts; health concerns might be reduced thereby, and by means of focused counseling and follow-up of contraceptive adopters; husband's opposition might be addressed through community-level campaigns and by increasing field-workers' sensitivity to this problem; and so forth. None of these obstacles appears to be immune to appropriately designed interventions, nor is there evidence that some are more susceptible to intervention than others (although this seems likely and should be the subject of further research). In short, programmatic priorities can be derived directly from the relative strength of the various obstacles.

\section{OBSTACLES TO CONTRACEPTIVE USE}

\section{Strength of the Motivation to Avoid Pregnancy}

The strength of attachment to the desire to terminate childbearing or postpone the next pregnancy clearly varies among women. Some women who indicate a desire to avoid pregnancy are relatively unconcerned about becoming pregnant, whereas others regard it as a highly undesirable outcome and, when asked, admit to numerous concerns and worries. Women who feel ambivalent about their stated desire may be especially susceptible to other factors, such as those reviewed below, that act against their practicing contraception. One important factor that can weaken the motivation to use a method is a perception of low risk of conceiving. Responses from women who indicate that they can no longer conceive (most of whom are older than 35) are discarded from analysis here. In quantitative analyses in other settings, weakly held preferences emerge as an important factor contributing to the preference-use gap in a DHS multicountry analysis of unmet need (Westoff and Bankole 1995) and in an in-depth study in Luzon, Philippines (Casterline et al. 1997). From the Punjab survey data, the following indicators of 
the strength of motivation to avoid pregnancy are selected: the desire to have no more children, in contrast with wanting to postpone the next birth (those who wish to stop are assumed to have stronger motivation); number of concerns about having another child; whether the woman would be distressed if she became pregnant in the near future; and the woman's perception of her husband's desire for another child, under the assumption that this perception will affect the strength of her commitment to her own desires.

\section{Knowledge and Awareness of Contraception}

Many potential informational barriers exist to contraceptive use. Women must be aware of the methods available, must know where supplies of these methods can be obtained and how much they cost (with the exception of nonsupply methods such as withdrawal and periodic abstinence), and they must know how to use the method they choose. In several cross-national analyses, these types of knowledge are strongly associated with unmet need for contraception (Bongaarts and Bruce 1995; Robey et al. 1996), and in India they affect the intention to use a method in the future (Mishra et al. 1999). In research on Pakistan, Siragelden et al. (1976) note that awareness of contraceptive methods was already high in the late 1960s, a point emphasized again in the research on reasons for nonuse carried out by Hashmi et al. (1993). This finding has led most analysts to conclude that knowledge barriers are relatively insignificant in Pakistan (Shah and Cleland 1993). The explanatory power of the following knowledge indicators is considered here: the number of modern and traditional methods that the woman knows and the woman's past use of contraceptives. (In this analysis, knowledge of sources of family planning services and supplies are considered indicators of access to services and are discussed below.)

\section{Costs of Contraceptive Use}

Social and Cultural Acceptability. In previous research conducted in Pakistan, the social, cultural, and religious unacceptability of contraception repeatedly emerged as an important obstacle to using a method. In an analysis of survey data from the 1960s and 1970s, Sirageldin et al. (1976) identify what they term "cultural and social constraints," and Shah and Shah (1984) find that the most common reason given for not using a contraceptive is religious concerns (reflecting what they term a negative climate 
of opinion). More recently, Hashmi et al. (1993) identify religious concerns as the second most common reason given for nonuse, and in their analysis of 1990-91 DHS data Mahmood and Ringheim (1996) show that religious conservatism is a strong negative correlate of contraceptive use. From this and other research, Shah and Cleland (1993) conclude that "deep ambivalence about family planning" stands among the most imposing barriers to increased practice of contraception in Pakistan. In this respect Pakistan may well be exceptional: We are not aware of empirical research from other settings in which the acceptability of contraception assumes such importance. Our indicators of the social and cultural acceptability of contraception are: the respondent's approval of family planning; her perception of the approval of in-laws; the number of modern methods the woman approves; her approval of withdrawal (use of which increased in the early 1990s, making a substantial contribution to the overall increase in prevalence, and as a non-supply method not affected by shortcomings in family planning services); her perception that use of a contraceptive method might provoke divine disapproval (including death of a child); religious concerns as a stated reason for not practicing contraception; and past practice of contraception, taking this as an indicator that the woman finds contraceptive use acceptable behavior. ${ }^{1}$

Husband's Opposition. Empirical research conducted during the 1990s makes evident that women's perception that their husbands oppose family planning is a dominant factor discouraging contraceptive practice in a wide variety of settings, including Egypt (El-Zanaty et al. 1999), Guatemala (Asturias de Barrios et al. 1998), India (Viswanathan et al. 1998; Mishra et al. 1999), Philippines (Casterline et al. 1997), and Nepal (Stash 1999). Although this view is also commonly held among researchers and program managers in Pakistan, previous research has been inconclusive on this point. In their early analysis of the 1968-69 National Impact Survey, Sirageldin et al. (1976) show that husband's approval of contraception is strongly associated with contraceptive use among women who want to avoid further childbearing, that is, women with unmet need. Shah and Shah (1984) and Hashmi et al. (1993), in comparable studies of reasons for nonuse, find, however, that a perception that the husband disapproves is provided far less often as a reason for nonuse than are religious concerns and fear of contraceptives' side effects on health. A husband's disapproval may reflect his fertility preferences or his other adverse feelings about contraception. On the question of the determining role 
of the husband's desire for more children, Mason and Smith (2000) show that husbands' preferences are more strongly associated with contraception than are wives' preferences (especially in the "most feudal" communities in Punjab), but that nevertheless they account for a relatively small fraction (around 10 percent) of unmet need for limiting family sizes. Another line of research focuses on spousal communication (about contraception and related issues) and finds that it is a good predictor of contraceptive use (Mahmood and Ringheim 1996) and fertility preferences (Mahmood and Ringheim 1997). ${ }^{2}$ From the 1996 Punjab data, we select the following as indicators of the husband's support of (or opposition to) contraception (all of these indicators are taken from interviews with women, and hence represent the wives' perceptions of their husbands' views): husband's desire for another child; husband's approval of family planning; the number of modern methods he approves; husband's approval of withdrawal; ease of discussing family planning with the husband; husband's opposition as a stated reason for not practicing contraception; and past use of a contraceptive, assuming that a woman is unlikely to have used a method in the past without her husband's approval.

Health Concerns. The same empirical studies carried out in diverse settings in the 1990s that highlight the determining role of women's perceptions that their husbands oppose contraception also reveal that a set of related health concerns constitutes a powerful obstacle to using a method (Bongaarts and Bruce 1995; Casterline et al. 1997; Asturias de Barrios et al. 1998; Viswanathan et al. 1998; Yinger 1998; El-Zanaty et al. 1999; Stash 1999). Judging from prior research conducted in Pakistan, this conclusion applies in this setting as well. In both Shah and Shah (1984) and Hashmi et al. (1993), fear of side effects on health is identified as one of the two most important explanations for nonuse. Here, we make use of the following measures: number of contraceptive methods thought to have bad side effects; side effects identified as an obstacle to use; and side effects as a stated reason for not practicing contraception.

Access to Contraceptive Services. One of the principal aims of this study is to broaden the investigation of the costs of contraceptive use to include the social, cultural, and health costs described above, which typically have not been well measured in survey research on contraception. In so doing, however, we do not intend to downplay the potential significance of poor access to high-quality family planning services. Access 
remains a pervasive problem in most developing societies (Robey et al. 1996), and Pakistan is no exception. Numerous studies have revealed that large segments of the population, concentrated in rural areas, face considerable difficulty in obtaining low-cost, highquality family planning services (see reviews in Robinson et al. 1981; Rukanuddin and Hardee-Cleaveland 1992; and Rosen and Conley 1996). Mahmood and Ringheim (1996) find that women's knowledge of sources of supplies is the strongest predictor of contraceptive use, as reported in the 1990-91 DHS data. In research conducted in the early 1990s, contraceptive prevalence rose substantially in six areas served by intensive community-based distribution projects, a finding consistent with the argument that poor services are a major barrier to use (Shelton et al. 1999). Our 1996 data collection in Punjab province did not include direct measurement of the service environment. Therefore, we must rely on respondents' reports. The indicators selected for this analysis are: the number of methods for which women know a source of supply; the proximity of the nearest services; and whether or not the respondent can visit a health facility unaccompanied.

The aim in this analysis is to assess, in quantitative terms, the relative magnitude of these various obstacles to the practice of contraception. We treat the six obstacles as separable and competing reasons for nonuse, but doing so is undoubtedly a simplification of reality. The qualitative research indicates clearly that each of these barriers is multidimensional in nature, a conclusion that also emerges from Stash's (1999) investigation of the causes of unmet need in Nepal (see also Nag 1984). Health concerns are a good example of this multidimensionality: As we learned from our exploratory qualitative interviews, fear of the side effects of contraceptives dissuades women from using them not only because of aversion to the expected physical discomfort but also because of the expected time and financial costs of managing the side effects, the potential loss of work time, the possibility of interference with spousal sexual relations, and a sense that the side effects signify divine disapproval. The multiple facets of health concerns, therefore, touch on other obstacles treated as distinct in the framework, such as anxiety about the acceptability of contraceptive use and respondents' perceptions that their husbands oppose family planning. Hence the design of this analysis entails a regrettable simplification, but we feel this cost is more than offset by our gaining the ability to offer a quantitative assessment of the relative strength of each obstacle. An explicit ranking of the 
obstacles, which we provide below, should be especially helpful for the setting of policy and program priorities.

\section{DATA AND METHODS}

The data analyzed in this paper were collected in 1996 in Punjab province, Pakistan by the Population Council, under the direction of the second and third authors. The survey used a probability sample of the entire province, and yielded a sample of 23 clusters (eight urban, 15 rural) from which 1,310 currently married women aged 20-44 and 554 of their husbands were interviewed successfully. Communities were sampled with unequal probability of selection, and therefore, sampling weights are applied throughout the analysis unless otherwise noted. For further details about the design of the survey, see Population Council (1997).

The principal objective of the 1996 study was to investigate the causes of unmet need for family planning. To this end, information was obtained on each of the factors identified in the previous section. To obtain such information, the survey questionnaire asked contraceptive-method-specific queries (Robinson and Cleland 1992) concerning the respondent's knowledge, approval (respondent and spouse), perceptions of access to services, and concerns about side effects; a block of items concerning the respondent's views about whether or not certain factors were important hindrances to practicing contraception in her community; and follow-up questions to the standard fertility-preference items that probed the degree of the respondent's attachment to the expressed preferences. These items were administered to all women, users and nonusers alike. In addition, nonusers were asked why they were not using a method at the time of the survey and, if they indicated no intention to use a method in the future, why this was so.

Additional information was collected on demographic and socioeconomic characteristics of the respondent and her household, including measures of economic status that have been shown to be associated with use of modern contraceptives in Pakistan (Mahmood 1992; Agha 2000). Two blocks of items inquired about the woman's degree

of autonomy and about the extent of her decisionmaking power in various domains of everyday and family life. These measures may be particularly important in Pakistan, given the overall low levels of female autonomy and participation in activities outside 
the home (Shah 1986; United Nations 1993; Sathar and Kazi 1997). Assuming that the measured demographic and socioeconomic variables accurately reflect the stage of the respondent's reproductive career and her social class, these further items concerning mobility and participation in household decisionmaking capture differences in women's ability to formulate and express reproductive intentions, their authority to make reproductive decisions, and their capacity to access the information and services required to implement those decisions.

Collectively, these items provide an unusually solid empirical foundation for testing hypotheses about how various perceived costs of contraception and the strength of motivation affect contraceptive practice. We are aware of no other survey data collected in Pakistan in recent years that contain the same combination of variables and, indeed, only a few equivalent data sets are available from any developing-country setting.

In an investigation of barriers to contraceptive use, the natural choice of dependent variable is current contraceptive-use status. From the standpoint of causal modeling, however, the cross-sectional nature of the survey data presents a problem. Contraceptive use is measured contemporaneously with the various perceptions listed above, and therefore, some ambiguity about cause and effect is inevitable: Have the woman's perceptions led to her decision to practice (or not practice) contraception, or vice versa? For example, are concerns about side effects a determinant, or a result, of using a method? The same can be asked about most of the measured indicators of central interest in this analysis (Robinson and Cleland 1992). Indeed, since contraceptive-use status may have been stable for some time preceding the interview, the contraceptive behavior of many women may have preceded the formation of the perceptions expressed in the survey interview. In all likelihood, the causality has operated in both directions, whereas our aim is to estimate one set of causal effects, that is, the effects of the obstacles to the decision to practice contraception.

To diminish this threat to the validity of the findings, we depart from most of the previous literature on reasons for nonuse of contraceptives and analyze the intention to use in the future among women not currently using a method. Several longitudinal analyses have shown women's stated intentions to be strongly associated with their later contraceptive behavior (for example, Bhatia 1982; Adler et al. 1990; Curtis and Westoff 
1996). To the extent that the intention to use is an accurate proxy for future contraceptive behavior, the causality is clarified and simplified: Contraceptive behavior is examined as a function of women's perceptions at an earlier time (that is, the time of the survey interview). In reality, stated intentions to use are not a pure proxy for future behavior; rather they are also influenced by other unmeasured attitudes and past experiences affecting the perceived obstacles that are the independent variables of central interest in this research. For this reason, in modeling the intention to use, we have not entirely resolved the problem of sorting out cause and effect. Nevertheless, by excluding current users and examining intentions about future behavior, we feel that we are on relatively firm footing in positing causal relationships.

We devise an intention-to-use variable akin to the unmet-need indicators commonly used in the research literature. The analysis is restricted to nonusers who express a desire to avoid pregnancy, that is, women who state that they want no more children or that they want to postpone the next birth for at least two years. For these women, we construct an indicator of whether or not they intend to use a contraceptive during the next two years. Women who want another child soon, women who perceive themselves to be infecund, women who are practicing contraception at the time of the survey, and women with missing information on a few explanatory variables are all dropped from the analysis, leaving 579 unweighted cases for analysis. Thirty-five percent of these women indicate an intention to use a contraceptive within two years. ${ }^{3}$

To estimate the effects of interest in an efficient and parsimonious fashion, we carry out structural equations modeling, treating the various obstacles to contraception as unobserved ("latent") variables (Bollen 1989). The full model contains several distinct components and is admittedly complex (with estimation requiring specialized software), but each component is relatively straightforward and resembles familiar regression analysis. The key feature of the approach is the assumption of the existence of latent variables, not observed directly but instead expressing themselves through responses to survey items. Any one of these items may be imperfectly measured, but collectively they are assumed to provide an adequate representation of the unobserved variable. This approach takes maximum advantage of the Punjab survey data, which contain multiple items associated with each of the hypothesized obstacles that may account for unmet need. 
The full model consists of three components, each of which is a set of regression equations: (1) measured indicators regressed on the latent variables (that is, the obstacles to contraception) (27 equations); (2) latent variables regressed on the background variables (six equations); and (3) intention to use regressed on the latent variables (one equation).

The first set of equations constitutes the so-called measurement model. As in all commonly used forms of factor analysis, in the measurement model the measured indicators should be viewed as the dependent variables and the latent variables as the independent variables. The regression coefficients estimated in the measurement model give a sense of the relative strength, or weighting, of the relationships between the latent variable and its measured indicators. These coefficients are, however, of limited interest for our purposes; they should be viewed as building blocks for the estimation of the "structural model." The second two sets of equations constitute the structural model. One set of equations in the structural model regresses the latent variables on the demographic and socioeconomic variables, which are assumed to be exogenous in this analysis. A further equation consists of the intention to use regressed on the six obstacles to contraception (the latent variables), and it is this equation that is of paramount concern in this research. Although the three sets of equations are separated for presentation purposes, they are estimated jointly. Values of the latent variables are not calculated directly, as they would be if indexes or scales were constructed from the measured indicators. Rather, given the posited relationships among the measured indicators and the latent variables, all coefficients of interest can be calculated, along with their standard errors. ${ }^{4}$

In this analysis, the latent variables are assumed to be continuous in nature. Our measured indicators, however, are a combination of continuous and categorical variables, and therefore, it is not appropriate to assume linear regressions throughout the model and conventional Gaussian multivariate normality. The estimation is, therefore, more challenging. We use the approach developed by Muthén over the past 15 years (Muthén 1983 and 1984; Muthén et al. forthcoming), as implemented in the software package Mplus (Muthén and Muthén 1998). The categorical indicators used in the measurement model must be either dichotomous or ordinal, a requirement met in the Punjab data. For these categorical indicators, the regression model can be viewed as a probit (binary or ordinal), yielding merely one parameter estimate for each effect of the latent 
variables even when the measured indicators are polytomous. In the portion of the structural model in which the latent variables serve as the dependent variables, because the latent variables are assumed to be continuous, all the regressions are linear regressions. To make the regression results more comparable across variables and equations, we present standardized coefficients. The statistical tests employ robust standard errors that take into account heteroskedasticity in the data. For details on the method of estimation (which is maximum likelihood via weighted least squares), see Muthén and Muthén (1998).

The following seven background variables are selected: number of living sons, size of residence, household wealth, years of schooling, the woman's decisionmaking autonomy, exposure to family planning messages on radio, and exposure to family planning messages on television. (Past use of contraceptives, which in the modeling is treated as one of the measured indicators of several of the obstacles to the practice of contraception, can be regarded as a further background variable.) In exploratory regressions, several other background variables measured in the 1996 survey proved to have no net effects: age of the respondent, the husband's years of schooling, and the dwelling's construction material (assumed to be indicative of household wealth). Some further comments are in order about the number of living sons, which is known to be a strong predictor of contraceptive use in Pakistan, reflecting the prevailing preference for sons over daughters (Khan and Sirageldin 1977; United Nations 1993; Mahmood and Ringheim 1996; Winkvist and Akhtar 2000). Most previous studies of the effects of son preference on reproductive behavior in Pakistan have examined effects that operate through fertility preferences. A different hypothesis is considered here: that among those who have already expressed a desire to stop or postpone childbearing, the strength of attachment to this preference is positively associated with the number of living sons.

\section{RESULTS}

The measured indicators of the six latent factors-strength of the motivation to avoid pregnancy, knowledge of contraception, and the four costs of practicing contraception, along with the socioeconomic, demographic, and women's autonomy variablesare listed in Table 1, which also shows the percentage distribution of the sample (unweighted) across the categories of each indicator (right-hand column) and the pro- 
portion intending to practice contraception, the converse of unmet need (middle column). With only a few exceptions noted below, none of these bivariate relationships runs counter to expectations. Large differentials in the intention to use, amounting to 20 percentage points or more, are apparent for one or more measured indicators of each of the six factors. The differentials are somewhat smaller for motivation to avoid pregnancy (comparatively weak associations are found between intention to use and concerns and worries about having another child) and health concerns. Among the specific indicators, the differentials are especially large for the respondent's approval of contraception, the number of modern methods approved, religious concerns as a reason for not using, husband's approval of contraception, the number of modern methods the husband is thought to approve, the ease of discussing family planning with the husband, and the number of methods for which sources of supply are known. Looking at the background variables in the final panel, the proportion intending to use a contraceptive is substantially higher among women with more living sons, urban women, women in wealthier households (that is, households with more possessions), women who have attended school, women who report greater decisionmaking power in household matters, and among those who recall family planning advertisements on radio or television.

The one set of differentials that do not conform to expectations are those for indicators of health concerns about contraception. Two of the indicators produce no differential in the intention to use, and the association with the number of methods thought to have bad health side effects is sharply positive. Although this latter result appears counterintuitive, in fact empirical data from contemporary developing societies commonly show an association between fear of methods' side effects and contraceptive use that works in this direction (for example, Biddlecom and Kaona 1998). The most plausible explanation for this empirical regularity is that familiarity with contraception, which naturally should be greater among experienced contraceptive users (former or current) and among those seriously contemplating future use, leads to greater awareness of the possible health consequences. Moreover, the structure of the 1996 inquiry in Punjab was such that only those women who were aware of specific methods of contraception were asked about whether they thought that their use caused bad side effects to health, a questionnaire design feature that induces a positive association between number of meth- 
Table 1 Among women surveyed, percentage intending to practice contraception in the future and percentage distribution of respondents, by categories of measured indicators, 1996 Punjab Unmet Need Survey

Category and

measured indicator
Percent intending

to use a method ${ }^{\text {a }}$
Percentage

distribution

of respondents

$(\mathrm{N}=579)^{\mathrm{b}}$

Motivation to avoid pregnancy

Desire for children

Wants more

Wants no more

Number of concerns about having another child

0

1

$2+$

Would be worried if she became pregnant

No

Yes

Husband's desire for children

Wants more soon

Wants more later

Wants no more

Knowledge/awareness of contraception

Number of modern methods known

$$
0-3
$$

4

5

Number of traditional methods known

0

$1+$

Acceptability of contraception

Approves of family planning

No

Yes

Perceives that in-laws approve

No

Yes

60 40 28

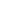


Table 1 (continued)

\section{Percentage}

distribution

Category and

Percent intending

of respondents

measured indicator

to use a method ${ }^{\mathrm{a}}$

$(\mathrm{N}=579)^{\mathrm{b}}$

Number of modern methods respondent approves of

0

10

25

1

37

24

2

37

20

$3+$

52

31

Approves of withdrawal

No

30

77

Yes

51

23

Thinks contraceptive use might provoke divine disapproval

No

Yes

Reason for not using a method: religious concerns

No

Yes

Perceptions of husband's attitudes

Husband approves of family planning

No

Yes

Number of modern methods of which husband approves

0

1

2

$3+$

Husband approves of withdrawal

No

Yes

Discussion of family planning with husband is

Difficult

Easy

Reason for not using a method: husband's opposition No

Yes
83 
Table 1 (continued)

\begin{tabular}{c} 
Percentage \\
distribution \\
of respondents \\
$(\mathrm{N}=579)^{\mathrm{b}}$ \\
\hline
\end{tabular}

Category and measured indicator
Percent intending

to use a method ${ }^{\mathrm{a}}$

Respondent's health concerns

Number of methods having bad side effects

0

1

2

$3+$

Side effects are an obstacle to use

No

Yes

Reason for not using a method: health concerns

No

Yes

Access to services

Number of methods for which sources of supplies are known

$0-1$

2-3

4

$5+$

Perceived proximity of nearest services

On foot, $<30$ minutes

On foot, $30+$ minutes

More distant

No facility

Can visit health facility alone

No

Yes

Background variables

Past use of contraceptives

Never used

Ever used 
Table 1 (continued)

\section{Percentage}

distribution

Category and

Percent intending

of respondents

measured indicator

to use a method ${ }^{\mathrm{a}}$

$(\mathrm{N}=579)^{\mathrm{b}}$

Number of living sons

0

25

13

1

29

30

$2+$

40

57

Area of residence

Rural

74

Urban

50

26

Number of household items owned

0

26

1

34

36

2

43

23

$3+$

41

15

Schooling (years)

0

$1+$

Number of matters in which respondent

can make household decision on her own ${ }^{c}$

0

1

2

$3+$
25

33

41

39

30

48

44

35
25

19

20

36

30

48

Exposed to family planning information on television

No

22

Yes

Total

100

aWeighted. ${ }^{\text {bUnweighted. }} \quad{ }^{\mathrm{c} R e s p o n d e n t s ~ w e r e ~ a s k e d ~ i f ~ t h e y ~ c o u l d ~ d e c i d e ~ o n ~ t h e i r ~ o w n ~ h o w ~}$ to spend part of the household income, whether to send their children to school, where to take a sick child, and whether they could buy new clothing for themselves.

Note: Sample consists of currently married women aged 20-44 not currently practicing contraception who perceive themselves to be fecund and who want to postpone the next birth or have no more children. Four respondents who lacked information on one or more of the measured indicators were dropped. 
ods known (itself positively associated with the intention to use) and number of methods thought to cause bad side effects. This finding is an excellent example of the problem of reverse causality - familiarity with contraception's affecting perceptions of contraception-discussed above. Evidently the decision to analyze intention to use, rather than contraceptive use per se, has not alleviated this problem entirely. The analysis includes indicators of knowledge and awareness of contraception, however. In the regression analysis, adjustment for this set of indicators should help contain some of the bias evident in Table 1.

The size of Table 1 makes clear the large number of measured indicators available for this analysis (23 indicators in all, plus the background variables), a distinctive and advantageous feature of the Punjab data. ${ }^{5}$ Each of the six latent variables is represented by three to seven measured indicators, as specified in the measurement model presented in Table 2. The structure of the measurement model is not quite as simple as Table 1 suggests: The husband's desire for another child is used as an indicator of both motivation and husband's attitudes, and past use of contraceptives is used as an indicator of knowledge, acceptability, and husband's attitudes. ${ }^{6}$

A close look at the estimates in Table 2 reveals that every one of the coefficients in the measurement model is significant at the 0.001 level. From the signs of the coefficients, the nature of the unobserved obstacle can be inferred. It is thereby apparent that the strength of motivation to curtail childbearing should have a positive effect on the intention to use a contraceptive; that knowledge is a matter of familiarity with contraception and also should have a positive effect on the intention to use a method; that social acceptability concerns approval of contraception and therefore should have a positive effect on the intention to use; that the wife's perception of her husband's attitudes captures aspects of the husband's views that should facilitate contraceptive use, and hence should have a positive effect on the intention to use; that the health-concerns indicator is a positive function of fears about detrimental side effects of contraceptives, and hence should have a negative effect on the intention to use; and, finally, that access to services is a matter of greater availability of services, and therefore should have a positive effect on the intention to use a method. In short, five of the six latent variables are expected to show positive effects on the intention to use. 
Table 2 Coefficients of measured indicators of latent variables that may act as obstacles to contraceptive use, by indicator, 1996 Punjab Unmet Need Survey

\begin{tabular}{|c|c|c|}
\hline Latent variable & $\begin{array}{l}\text { Measured indicator } \\
\left(\mathrm{N}=579^{\mathrm{a}}\right)\end{array}$ & Coefficient $^{\mathbf{b}}$ \\
\hline $\begin{array}{l}\text { Motivation to avoid } \\
\text { pregnancy }\end{array}$ & $\begin{array}{l}\text { Desires no more children } \\
\text { Number of concerns about having another child } \\
\text { Would be worried if became pregnant } \\
\text { Husband desires no more children }\end{array}$ & $\begin{array}{l}0.77^{c} \\
0.68^{* *} \\
0.82^{* *} \\
0.61^{* *}\end{array}$ \\
\hline Knowledge & $\begin{array}{l}\text { Number of modern methods known } \\
\text { Number of traditional methods known } \\
\text { Past use of contraceptives }\end{array}$ & $\begin{array}{l}0.56^{\mathrm{c}} \\
0.78^{* *} \\
0.49^{* *}\end{array}$ \\
\hline Acceptability & $\begin{array}{l}\text { Respondent approves of family planning } \\
\text { Perceives that in-laws approve } \\
\text { Number of modern methods of which } \\
\text { respondent approves } \\
\text { Respondent approves of withdrawal } \\
\text { Thinks contraceptive use might provoke } \\
\text { divine disapproval } \\
\text { Religious concerns given as reason for not } \\
\text { using a method } \\
\text { Past use of contraceptives }\end{array}$ & $\begin{array}{l}0.85^{\mathrm{c}} \\
0.58^{* *} \\
0.64^{* *} \\
0.44^{* *} \\
-0.21^{* *} \\
-0.79^{* *} \\
0.25^{* *}\end{array}$ \\
\hline $\begin{array}{l}\text { Respondent's perception } \\
\text { of husband's attitudes }\end{array}$ & $\begin{array}{l}\text { Husband approves of family planning } \\
\text { Number of modern methods of which } \\
\text { husband approves } \\
\text { Husband approves of withdrawal } \\
\text { Husband desires no more children } \\
\text { Ease of discussing family planning with husband } \\
\text { Husband's opposition given as reason for not } \\
\text { using a method } \\
\text { Past use of contraceptives }\end{array}$ & $\begin{array}{l}0.95^{\mathrm{c}} \\
0.81^{* *} \\
0.31^{* *} \\
0.26^{* *} \\
0.81^{* *}\end{array}$ \\
\hline $\begin{array}{l}\text { Respondent's health } \\
\text { concerns }\end{array}$ & $\begin{array}{l}\text { Number of methods thought to have bad side effects } \\
\text { Side effects are obstacle to use } \\
\text { Health concerns given as reason for not } \\
\text { using a method }\end{array}$ & $\begin{array}{l}0.75^{\mathrm{c}} \\
0.54^{* *}\end{array}$ \\
\hline Access to services & $\begin{array}{l}\text { Number of methods for which respondent } \\
\text { knows source } \\
\text { Perceived proximity to nearest services } \\
\text { Respondent can visit health facility alone }\end{array}$ & $\begin{array}{c}0.16^{\mathrm{c}} \\
-0.26^{* *} \\
0.47^{* *}\end{array}$ \\
\hline
\end{tabular}

\footnotetext{
*Significant at $\mathrm{p}<0.001$ (one-sided).
}

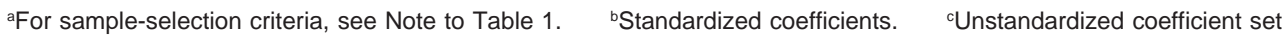
to 1.00 , for model identification; therefore, statistical test is inappropriate (see Maruyama 1998). 
The measurement model in Table 2 is of lesser interest in this research than the structural model presented in Table 3. The six equations in the top panel of Table 3 consist of the effects of the seven background variables on the latent variables (that is,

Table 3 Structural model equations for latent variables showing coefficients of the effects of background variables, and for intention to use a contraceptive showing coefficients for the effects of latent variables, 1996 Punjab Unmet Need Survey

\begin{tabular}{|c|c|c|c|c|c|c|}
\hline \multirow[b]{2}{*}{ Variable } & \multicolumn{6}{|c|}{ Latent variable $^{a}$} \\
\hline & Motivation & Knowledge & $\begin{array}{l}\text { Accep- } \\
\text { tability }\end{array}$ & $\begin{array}{c}\text { Husband's } \\
\text { attitudes }\end{array}$ & $\begin{array}{c}\text { Health } \\
\text { concerns }\end{array}$ & $\begin{array}{r}\text { Access to } \\
\text { services } \\
\end{array}$ \\
\hline \multicolumn{7}{|l|}{ Background variable } \\
\hline Number of living sons & $0.54 * *$ & - & - & $0.12 * *$ & - & - \\
\hline Urban residence & $0.08 *$ & $0.28 * *$ & $0.12 * *$ & 0.03 & $0.14 *$ & $0.32 *$ \\
\hline Household items $(2+)$ & - & - & - & $0.12 *$ & - & - \\
\hline Schooling $(1+$ years $)$ & 0.00 & $0.22 * *$ & $0.11 * *$ & 0.00 & -0.01 & $0.45 * *$ \\
\hline \multicolumn{7}{|l|}{$\begin{array}{l}\text { Makes own household } \\
\text { decisions }^{\mathrm{b}}\end{array}$} \\
\hline 2 & $0.18 * *$ & $0.17 * *$ & $0.12 * *$ & 0.04 & -0.01 & $0.39 * *$ \\
\hline $3+$ & $0.18 * *$ & $0.28 * *$ & $0.08 *$ & $0.10^{*}$ & $0.16^{*}$ & $0.79 * *$ \\
\hline $\begin{array}{l}\text { Exposed to family planning } \\
\text { information on radio }\end{array}$ & g & $0.07 *$ & $0.06^{*}$ & - & - & - \\
\hline $\begin{array}{l}\text { Exposed to family planning } \\
\text { information on television }\end{array}$ & g & $0.14 * *$ & $0.29 * *$ & - & - & - \\
\hline
\end{tabular}

\section{Latent variable}

Effects on intention to use ${ }^{\mathrm{a}}$

Motivation

$-0.03$

Knowledge/awareness of contraception

$0.30 * *$

Acceptability of contraception

$0.47 * *$

Husband's attitudes

$0.46^{* *}$

Health concerns

0.04

Access to services $-0.25$

* Significant at $\mathrm{p}<0.05 ; * * \mathrm{p}<0.001 . \quad-\quad-$ Not in equation. $\quad(\mathrm{N})=579$.

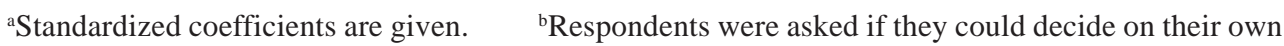
how to spend part of the household income, whether to send their children to school, where to take a sick child, and whether they could buy new clothing for themselves.

Notes: For sample-selection criteria, see Note to Table 1. 
the obstacles to contraception). With the exception of husband's attitudes and health concerns, all of the obstacles vary significantly according to four or more of these background variables. None of these effects is surprising. Overall, the respondent's schooling is a weaker explanatory variable than are urban residence and the woman's decisionmaking autonomy. From the latter result, one might conclude that greater insight about the determining role of women's status is obtained from focused measures of female autonomy than from more global and diffuse variables such as schooling (a conclusion consistent with other recent empirical research, for example, Jejeebhoy 1996; Sathar and Kazi 1996).

For our purposes, the key coefficients are those expressing the effects of the six obstacles on the intention to use (shown in the lower panel of Table 3). Three of these are statistically significant - the effects of knowledge, acceptability, and husband's attitudes. Of the remaining three, the effects of motivation and health concerns are close to zero, and the effect of access is negative. The major conclusion from Table 3, therefore, is that the key obstacles to contraceptive use in Punjab are the perceived social and cultural unacceptability of contraception and wives' perceptions that their husbands are opposed to (or, at the least, not supportive of family planning). These two obstacles are essentially equal in strength. About two-thirds as strong, according to the standardized coefficients, is lack of contraceptive knowledge.

The dominance of acceptability and husband's attitudes is consistent with our interpretation of the qualitative interviews we conducted and, on the whole, with previous research results for Pakistan. Missing from results shown in Table 3, but prominent in our conclusions drawn from the qualitative interviews and from the existing research literature, are women's fears of the detrimental side effects of contraceptives on health. That outcome is discussed below. The existing literature is, to some degree, ambivalent as to whether husbands' attitudes, expressed or perceived, constitute a major barrier to Pakistani women's ability to implement their fertility preferences by practicing contraception. Studies that explicitly or implicitly downplay the dominance of these variables include Hashmi et al. (1993), Shah and Shah (1984), and Mason and Smith (2000). Our results are emphatic on this point: Among women who wish to avoid becoming pregnant, their perceptions of their husbands' views is matched only by their concerns about 
the acceptability of contraception as a predictor of their intention to use a contraceptive in the future. The large effect of acceptability is expected; many studies conducted in Pakistan, reviewed above, have stressed the salience of social and religious concerns.

The variables concerning husbands' views are derived entirely from interviews with their wives; that is, these are wives' perception of the attitudes and preferences of their husbands. The 1996 data collection in Punjab included interviews with a subset of husbands ${ }^{7}$ who were administered essentially the same questionnaire as that presented to their wives. With these data, the husbands' responses can be compared with their wives' perceptions to assess their accuracy. Table 4 shows this comparison for the variables used in this analysis. Considerable discrepancy is found between the wives' perceptions and the responses provided by their husbands. Clearly, such spousal discordance is not limited to Pakistan (Thompson 1990; Becker 1996; Bankole and Singh 1997). Because gender stratification is especially sharp in Pakistan, however (as compared, for example, with that in other South and Southeast Asian countries-see Mason and Smith 2000; see also United Nations 1993 and Sathar and Kazi 1997), one would expect wives' misperceptions of husbands' views to be unusually pronounced. Most dramatic is the discrepancy regarding husband's approval of family planning: Among couples in which the wives felt that their husbands did not approve of contraception, 61 percent of the husbands indicated that they did approve of it. The discrepancies in Table 4 are larger for the variables that couples are less likely to have discussed: For example, wives more accurately perceive their husbands' desires to stop than to space childbearing. Because fertility limitation is the more consequential step, we suspect that couples are more likely to discuss it than to discuss spacing their children. Interestingly, husbands' disapproval of withdrawal (associated with a lower likelihood of intending to use, as shown in Table 1), is more likely than their approval of it to be perceived accurately by their wives. Finally, whereas most husbands report that communication about family planning is easy, they are more likely to express this opinion if their wives hold that view also. The wife-husband comparisons in Table 4 suggest that the effects of the husbands' variables in the regression analysis reflect both genuine attitudes and preferences of the husband that work against adopting a contraceptive method and erroneous perceptions on the part of the wife. 
Table 4 Percentage of husband's reported attitudes toward contraception that match wife's perception of husband's attitudes, 1996 Punjab Unmet Need Survey

As reported

\section{by husband}

Wife's perception

$(\mathrm{n}=\mathbf{2 4 8})^{\mathrm{a}}$

Total

Husband approves of family planning

No

No

Yes

Yes

39

61

100

31

69

100

Number of modern methods of which husband approves

0

$\begin{array}{cccc}\mathbf{0} & \mathbf{1 - 2} & \mathbf{3 +} & \\ 58 & 23 & 19 & 100 \\ 32 & 53 & 15 & 100 \\ 48 & 31 & 21 & 100\end{array}$

Husband approves of withdrawal

No

No Yes

Yes

86

14

100

65

35

100

Husband desires another child

Soon

Soon

49

Later

No more

Later

50

13

38

100

Wants no more

8

31

19

100

10

82

100

Spousal discussion of family planning is

Difficult

Easy

Difficult

40

60

100

Easy

32

68

100

${ }^{a}$ The selection criteria for women are the same as those specified in Note to Table 1. This table is calculated for the subset of those women whose husbands were interviewed successfully. See Population Council (1997) for details on sampling procedures.

Surprising results in the structural model of Table 3 are the weak effects on the intention to use of strength of motivation to avoid pregnancy and health concerns. In the case of motivation, the moderately strong bivariate associations evident in Table 1 do not retain their power with multivariate controls. The confounding effects of obstacles such as the acceptability of contraception and the husband's views of contraception appear to account for the bivariate associations between the intention to use and strength 
of motivation (as represented by items such as the desire for another child and concerns about having another child). In this instance, multivariate modeling provides a revised and clearer picture of the relative magnitude of hypothesized effects. The message from the regression results in Table 3 is that strength of motivation to avoid pregnancy, as measured in the Punjab survey, has little bearing on contraceptive intentions, once other determining factors are taken into account.

In the discussion of results shown in Table 1 with regard to respondents' health concerns, we pointed out that the bivariate associations were not as expected, in all likelihood because of a reverse causality in which familiarity with contraception makes women more aware of their negative side effects. With controls for other variables in Table 3, including knowledge of contraceptives, the positive effects of the indicators of health concerns evident in the bivariate analysis of Table 1 have been nullified. Nevertheless, our hypothesis that anxieties about detrimental health consequences are a serious impediment to contraception is not substantiated. We are not convinced that these results provide a valid assessment of the determining role of health concerns in contraceptive decisionmaking in Pakistan. The widespread concern about adverse health repercussions that is evident in both the qualitative interviews and in the survey data collected in Punjab in 1996 must, we feel, act as a serious obstacle to the adoption and continued use of contraceptives. This concern may be expressed as much, or more, in the choice of a contraceptive method as in the decision to practice contraception per se. Methods such as withdrawal, the condom, and periodic abstinence have been relatively popular in Pakistan in the 1990s, contributing significantly to the recent increase in contraceptive prevalence (NIPS/LSHTM 1998). In-depth research has revealed that a common reason for choosing withdrawal is the absence of side effects as compared, for example, with hormonal and surgical methods (Ministry of Population Welfare and Population Council 1998). By this reasoning, the results in the lower panel of Table 3 may not be misleading: As of the mid-1990s, fear of side effects may have far greater influence on method choice than on the decision to use a contraceptive, hence the negligible effect on the intention to use a method.

In the case of access to services, again questions can be raised about the adequacy of measurement in the Punjab survey data, as mentioned above. Complaints 
about inaccessible and low-quality services were common in the qualitative interviews we conducted in 1996, and other independent studies carried out in the past five years have continued to document a seriously deficient, albeit improving, family planning service environment (Rosen and Conley 1996; Ministry of Population Welfare 1999). Inadequate access to services is especially pronounced in rural areas. Moreover, intervention studies show that improvements in services result in substantial increases in contraceptive prevalence (Shelton et al. 1999). Table 3 may, nevertheless, be correct in showing that access to services constitutes a less imposing barrier to contraceptive use for Punjabi women than do some of the other obstacles examined here, such as the social and cultural acceptability of contraceptives and users' perceptions of their husbands' views regarding family planning. That the modest effect of access is negativethat is, that greater access discourages future contraceptive use-as suggested by the estimates in Table 3 is harder to accept, however. Perhaps women who intend to use a method are more cognizant of the inaccessibility of family planning services and are therefore more likely to find existing services less than ideally situated. In any case, this finding for Punjab resembles results from other settings: When asked directly, women rarely give much weight to poor access to services as an explanation for their unwillingness to adopt contraception or for their discontinuation of contraceptive practice (Bongaarts and Bruce 1995; Westoff and Bankole 1995; Mishra et al. 1999).

\section{CONCLUSION AND IMPLICATIONS}

The principal aim of this study is to assess the relative strength of a set of obstacles to practicing contraception in Pakistan. Our concern is those factors that prevent women from translating a desire to avoid becoming pregnant into contraceptive practice. In adopting this focus, we ignore fertility demand as a fundamental force limiting contraceptive prevalence. The PDHS and other survey data indicate that Pakistani women still want to have four or five children, on average. So long as this family-size ideal prevails, fertility will not fall to low levels in Pakistan, and contraceptive prevalence will not attain the relatively high levels now observed in most countries in Asia (Sathar and Casterline 1998). Even under current patterns of fertility demand, however, ample scope exists for substantial increase in contraceptive prevalence (and for corresponding 
declines in fertility), because a large fraction of Pakistani women are not practicing contraception despite their desire to avoid pregnancy, that is, these women have an unmet need for family planning. The widespread discrepancy between fertility preferences and contraceptive use is addressed in this research.

In analysis of survey data collected in Punjab province in 1996, we carried out a quantitative assessment of the reasons for this gap between preferences and use. The survey contains unusually detailed measurements of the perceived costs of contraceptive use, as well as measurements of fertility motivation that go beyond the standard for national surveys such as the DHS. From these data, we extracted blocks of items representing obstacles to contraceptive use. Treating these blocks of items as measured indicators of unobserved variables in structural equation modeling, we estimate net effects of each obstacle on the intention to use a contraceptive in the near future (the two years subsequent to the survey). From this modeling, clear findings emerge: The two most important obstacles to implementing fertility preferences in contraceptive practice is the feeling that such behavior would be unacceptable on social or cultural grounds and women's perception that such behavior would conflict with their husbands' fertility preferences or views about family planning. Also of some importance, but distinctly weaker than these two obstacles, is inadequate knowledge and awareness of contraception. The remaining three obstacles do not show statistically significant effects on the intention to use a method. From an analytical standpoint, the analysis produced a satisfying outcome: We can distinguish clearly those factors that carry substantial weight from those factors that are relatively inconsequential in their impact.

Although the primary motivation for undertaking this research was to improve our understanding of the determinants of contraceptive behavior in Pakistan, the results have larger implications for the field. For 25 years, the dominant paradigm in research on family planning in contemporary developing societies has been the Easterlin Synthesis Framework (Easterlin 1975), which posits that two sets of factors bear directly on the decision to exercise deliberate fertility regulation, namely the desire to avoid becoming pregnant and the costs (defined broadly) of birth control. Among its many virtues, the synthesis framework offers a parsimonious explanation for the widespread lack of fit between the desire to limit or stop childbearing and contraceptive practice: that the gap 
will occur when the motivation to avoid pregnancy is overwhelmed by one or more costs of fertility regulation. These costs may already have been experienced by women or couples, or they may be anticipated. In either case, if the perceived costs are high enough, the woman or couple will resist contraceptive practice despite a desire to avoid another pregnancy (in the short term or indefinitely).

In view of the dominant status of this framework, surprisingly little research has been conducted (especially quantitative empirical research) on the full array of hypothesized contraceptive costs. In part, the lack of such research can be explained by the difficulty of measuring these costs; indeed, some of them are intrinsically nearly impossible to measure. The conclusion is hard to avoid, however, that the scant empirical attention to the magnitude of contraceptive costs and their effects on contraceptive decisionmaking reflects less than full respect for the potential power of the various possible obstacles to contraceptive use. In the design of the 1996 survey in Punjab province, we made a concerted effort to devise indicators of a wide range of obstacles. As a result of this effort, the regression analysis can draw on a large number of measures. In the Punjab data, the measurement of motivation might be viewed as unsatisfactory-a point that we would not entirely dispute; and the measurement of contraceptive costs is far from complete - a point we would also readily concede. Nevertheless, this research has an advantage over previous approaches in its systematic treatment of contraceptive costs. We encourage other researchers to explore a wide range of obstacles to contraceptive use, and, if possible, to go beyond those detailed here.

As we noted above, our findings are generally consistent with other research conducted in Pakistan during the past two decades. What sets this research apart from previous research is the assignment of explicit weights to the obstacles, with women's perceptions of their husbands' attitudes and preferences assuming a more dominant position in our results. In part, this result may reflect differences in research methodology, but it might be indicative of changes that have occurred in Pakistan during the 1990s, when women became better informed about contraception and more prepared to regard it as a viable option. We suspect that such changes were relatively more intense in Punjab province than elsewhere in Pakistan. The data indicate that women's perceptions of their husbands' views are not entirely accurate, that they perceive their husbands to have 
more negative views toward family planning than is the case. This finding provides some basis for suggesting that husbands' opposition will become a weaker obstacle in the coming years in Pakistan. We stress that the findings from this study pertain to a specific historical juncture and, moreover, are based on data from only one province (albeit the most populous). The ranking of factors may differ in more remote provinces such as Baluchistan, where access to services in particular may rank higher in the ladder of reasons for unmet need.

The implications of these findings for policy formulation and program development are clear. Pakistani women face several obstacles to implementing their fertility preferences. Some consensus has been reached on how the availability and quality of family planning services can be improved (Shelton et al. 1999), but achieving this goal is, of course, another matter. Less is known about how policies and programs can overcome the nonaccess obstacles. In particular, it is clear that husbands' attitudes (their approval and intentions) and wives' assessment of them are of overriding importance, and indeed some would view this factor as an almost insurmountable obstacle to satisfactory resolution of women's preference-use gap. This view would be too pessimistic. Ample evidence indicates that an increasing fraction of Pakistani men are strongly motivated to implement their own and their wives' fertility preferences through contraceptive practice. Moreover, husbands' and wives' preferences tend to be in close agreement. A discernible transformation of men's views toward fertility regulation is under way in Pakistan; the conviction is growing among men that family size must be limited, above all for economic reasons but also for health reasons (Levack and Rahim 1998; Sathar and Casterline 1998). One concrete indication is that nearly one-half of couples practicing contraception are using methods that require male cooperation (the condom, periodic abstinence, and withdrawal) (NIPS/LSHTM 1998), and, as noted above, increase in the use of these methods has made a substantial contribution to the increase in contraceptive prevalence during the 1990s.

Although the majority of husbands surveyed approve of family planning, nevertheless Pakistani men continue to harbor many misgivings about limiting fertility and practicing contraception (Bhatti and Hakim 1996). Although women appear to have an exaggerated impression of their husbands' opposition, undoubtedly a significant portion 
of perceived male resistance is real (Population Council 1997). Exacerbating the problem, and to some degree accounting for it, is the segregation of domains of women and men, with reproduction clearly falling into the sphere of women (Kazi and Sathar 1997). Therefore, communication about reproduction and responsibility for day-to-day decisions pertaining to reproduction and to reproductive health have been largely restricted to women. For decades women in Pakistan have been the focus of government services and of information, education, and communication (IEC) campaigns. Recognizing that the problem is a combination of misperceptions of husbands' views and genuine opposition on the part of men, we believe that two types of strategies to overcome the obstacle that men present are implied: one set to improve spousal communication (about contraception, childbearing, and related issues) (Mahmood and Ringheim 1997), and the second to change men's attitudes (about the desirability of large families and about contraception). The former might include activities that "break the ice" where communication is especially constrained (possibly through well-designed IEC campaigns), whereas the latter would include efforts to educate men about the risks associated with having large families compared with the risks of contraceptive use. A different, although not contradictory, strategy is to weaken men's predominant role in reproductive decisionmaking, through activities that empower women to negotiate choices. Although a shift in the gender balance of power may follow from larger social change, including broadened opportunities for schooling and paid employment, this transition can be facilitated by the expansion and improvement in reproductive health services that, among other things, provide women with knowledge about how, when, and where family planning methods can be obtained. One means of making providers, especially community-based health workers, more sensitive to the implications of gender stratification as an obstacle to women's reproductive health is to train them to address issues that encompass their clients' family and social situations. At present, such services are driven by providers' own perceptions of their clients' needs rather than by an assessment based on information gleaned from clients about their home realities and constraints.

Overcoming men's and women's entrenched misgivings about the social and cultural acceptability of contraception requires a different set of initiatives. Focused IEC campaigns, through the mass media and local efforts, can emphasize that family plan- 
ning is not contrary to Islam and, more important, can be in the best interests of women, men, and their children, and that it is ethically sound behavior. The most powerful counterforce to concerns about the acceptability of contraception, however, may be the increasing fraction of couples who have practiced contraception. Increased prevalence that results from the reduction of other obstacles such as health concerns and poor services will, in turn, heighten the general perception that contraception is an acceptable choice for couples to make. Another consequence of expanding prevalence is likely to be the diffusion of information about contraception, which will help to overcome obstacles associated with limited awareness of methods, side effects, and sources of supply.

\section{Notes}

1 Past use is also considered as an indicator of knowledge and awareness, as indicated above, and of husband's opposition, as indicated in the next paragraph. The statistical approach used in this analysis permits us to regard specific measured indicators as indicative of more than one underlying obstacle to contraception.

2 Mahmood and Ringheim concede that the direction of causality underlying the association between spousal communication and contraception is uncertain.

3 The number of women dropped from the total sample of 1,310 because of each of the specified restrictions, applied sequentially, is as follows: wants a child soon, 285; infecund, 64; using a method, 378; and missing information, 4.

4 For a more complete presentation of this approach, including a discussion of technical issues, the reader is referred to textbooks such as Bollen (1989). Maruyama (1998) offers a less technical introduction.

5 Only a few other measured indicators of latent factors were considered, but they were dropped in the interest of parsimony once their net effects were found to be not statistically significant. Given the large number of parameters to be estimated in relation to the number of observations and the large proportion of measured indicators that are categorical (which further reduces the statistical power in this type of estimation), the fact that so few effects were found to be insignificant is a 
testament to the overall quality of measurement and supportive of the concept that has guided the design of this research.

6 We also estimated models in which past use served as an indicator of health concerns and access. The statistical tests failed to support the addition of these effects to the measurement model.

7 See Population Council (1997) for a discussion of the sample design and sampling results.

\section{References}

Adler, Nancy E., Susan M. Kegeles, Charles E. Irwin, and Charles Wibbelsman. 1990. "Adolescent contraceptive behavior: An assessment of decision processes." Journal of Pediatrics 116(3): 463-471.

Agha, Sohail. 2000. "Is low income a constraint to contraceptive use among the Pakistani poor?" Journal of Biosocial Science 32(2): 161-175.

Asturias de Barrios, Linda, Idalma Mejia de Rodas, Isabel Nieves, Jorge Matute, and Nancy Yinger. 1998. Unmet Need for Family Planning in a Peri-Urban Community of Guatemala City. Washington, DC: International Center for Research on Women.

Bankole, Akinrinola and Susheela Singh. 1997. "Couples' fertility and contraceptive decision-making in developing countries: Hearing the man's voice." International Family Planning Perspectives 24(1): 15-24.

Becker, Stan. 1996. "Couples and reproductive behavior: A review of couple studies." Studies in Family Planning 27(6): 291-306.

Bhatia, Shushum. 1982. "Contraceptive intentions and subsequent behavior in rural Bangladesh." Studies in Family Planning 13(1): 24-31.

Bhatti, Mansoor Ul Hassan and Abdul Hakim. 1996. Male Attitudes and Motivation for Family Planning in Pakistan. Islamabad: National Institute of Population Studies.

Biddlecom, Ann E. and Fred Kaona. 1998. "The nature of unmet need for contraception in an urban African setting." Paper presented at the International Union for the 
Scientific Study of Population seminar on Fertility Transition in sub-Saharan Africa, Nairobi, 2-4 November.

Bollen, Kenneth A. 1989. Structural Equations with Latent Variables. New York: John Wiley \& Sons.

Bongaarts, John and Judith Bruce. 1995. "The causes of unmet need for contraception and the social content of services." Studies in Family Planning 26(2): 57-75.

Casterline, John B., Aurora E. Perez, and Ann E. Biddlecom. 1997. "Factors underlying unmet need for family planning in the Philippines." Studies in Family Planning 27(3): 173-191.

Curtis, Siân L. and Charles F. Westoff. 1996. "Intentions to use contraceptives and subsequent contraceptive behavior in Morocco." Studies in Family Planning 27(5): 239-250.

Easterlin, Richard. 1975. "An economic framework for fertility analysis." Studies in Family Planning 6(2): 54-63.

El-Zanaty, Fatma, Ann Way, Sunita Kishor, and John Casterline. 1999. Egypt Indepth Study on the Reasons for Nonuse of Family Planning. Cairo: National Population Council.

Hashmi, Sultan S., Khushnood Alam, and Aysha Sheraz. 1993. Non-users and Unmet Need for Contraception. Islamabad: National Institute of Population Studies.

Hermalin, Albert I. 1983. "Fertility regulation and its costs: A critical essay." In The Determinants of Fertility in Developing Countries. Eds. R. Bulatao and R. Lee. New York: Academic Press. Volume 2, pp. 1-53.

Jejeebhoy, Shireen. 1996. "Women's autonomy and reproductive behaviour in India: Linkages and influence of sociocultural context." Paper presented at the International Union for the Scientific Study of Population seminar on Comparative Perspectives on Fertility Transition in South Asia, Islamabad, 16-19 December.

Kazi, Shahnaz and Zeba Sathar. 1997. "Pakistani husbands and wives: Different productive and reproductive realities?" Paper presented at the annual meeting of the Population Association of America, Washington, DC, 28-30 March.

Khan, M. Ali and Ismail Sirageldin. 1977. "Son preference and the demand for additional children in Pakistan." Demography 14(4): 481-496. 
Levack, Andrew and Tariq Rahim. 1998. "The concept of men as partners in Pakistan." Populi 25(4): 6-8.

Mahmood, Naushin. 1992. "Motivation and fertility control behaviour in Pakistan." Pakistan Development Review 31(2): 119-144.

Mahmood, Naushin and Karin Ringheim. 1996. "Factors affecting contraceptive use in Pakistan." Pakistan Development Review 35(1): 1-22.

_ . 1997. "Knowledge, approval and communication about family planning as correlates of desired fertility among spouses in Pakistan." International Family Planning Perspectives 23(3): 122-129.

Mason, Karen Oppenheim and Herbert L. Smith. 2000. “Husbands' versus wives' fertility goals and use of contraception: The influence of gender context in five Asian countries." Demography 37(3): 299-311.

Maruyama, Geoffrey M. 1998. Basics of Structural Equation Modeling. Thousand Oaks, California: Sage Publications.

Ministry of Population Welfare. 1999. Population and Development: Pakistan Country Report for ICPD +5. Islamabad: Ministry of Population Welfare, Government of Pakistan.

Ministry of Population Welfare and Population Council. 1998. "A Qualitative Investigation into the Use of Withdrawal." Research Report No. 6. Islamabad: Population Council.

Mishra, Vinod K., Robert D. Retherford, P.S. Nair, and Griffith Feeney. 1999. "Reasons for Discontinuing and Not Intending to Use Contraception in India." National Family Health Survey Subject Reports No. 13. Mumbai, India: International Institute for Population Sciences.

Muthén, Bengt O. 1983. "Latent variable structural equation modeling with categorical data." Journal of Econometrica 22: 48-65.

— 1984. "A general structural equation model with dichotomous, ordered categorical, and continuous latent variable indicators." Psychometrika 49: 115-132.

Muthén, Bengt O. and Linda K. Muthén. 1998. Mplus: The Comprehensive Modeling Program for Applied Researchers. Los Angeles: Muthén and Muthén. 
Muthén, Bengt O., S.H.C. du Toit, and D. Spisic. Forthcoming. "Robust inference using weighted least squares and quadratic estimating equations in latent variable modeling with categorical and continuous outcomes." Psychometrika.

Nag, Moni. 1984. "Some Cultural Factors Affecting Costs of Fertility Regulation." Рориlation Bulletin No. 17. New York: United Nations.

National Institute of Population Studies (NIPS) and IRD/Macro International. 1992. Pakistan Demographic and Health Survey 1990/1991. Columbia, MD: IRD/Macro International.

National Institute of Population Studies (NIPS) / London School of Hygiene and Tropical Medicine (LSHTM). 1998. Pakistan Fertility and Family Planning Survey 1996-1997. Islamabad: National Institute of Population Studies.

Population Council. 1997. The Gap Between Reproductive Intentions and Behaviour: A Study of Pakistani Men and Women. Islamabad: Population Council.

Robey, Bryant, John Ross, and Indu Bhushan. 1996. "Meeting Unmet Need: New Strategies.” Population Reports, Series J, No. 43. Baltimore: The Johns Hopkins University.

Robinson, Warren and John Cleland. 1992. "The influence of contraceptive costs on the demand for children.” In Family Planning Programmes and Fertility. Eds. James Phillips and John Ross. Oxford: Clarendon Press. Pp. 175-207.

Robinson, Warren C., Makhdoom A. Shah, and Nasra M. Shah. 1981. "The family planning program in Pakistan: What went wrong?" International Family Planning Perspectives 7(3): 85-92.

Rosen, James E. and Shanti R. Conley. 1996. Pakistan's Population Program: The Challenge Ahead. Country Study Series No. 3. Washington, DC: Population Action International.

Rukanuddin, Abdul Razzaque and Karen Hardee-Cleaveland. 1992. "Can family planning succeed in Pakistan?” International Family Planning Perspectives 18(4): $142-146$.

Sathar, Zeba and John B. Casterline. 1998. "The onset of fertility transition in Pakistan." Population and Development Review 24(4): 773-796. 
Sathar, Zeba and Shahnaz Kazi. 1996. "Women's autonomy and the onset of fertility change in rural Pakistan: The significance of gender inequality across communities." Paper presented at the annual meeting of the Population Association of America, New Orleans, 9-11 May.

_. 1997. Women's Autonomy, Livelihood and Fertility in Rural Punjab. Islamabad: Pakistan Institute of Development Economics.

Shah, Iqbal H. and John G. Cleland. 1993. "High fertility in Bangladesh, Nepal, and Pakistan: Motives vs. means." In The Revolution in Asian Fertility: Dimensions, Causes, Implications. Eds. R. Leete and I. Alam. Oxford: Clarendon Press. Pp. 175-207.

Shah, Nasra. 1986. Pakistani Women. Islamabad: Pakistan Institute of Development Economics.

Shah, Nasra M. and Makhdoom A. Shah. 1984. "From non-use to use: Prospects of contraceptive adoption." In Fertility in Pakistan: A Review of Findings from the Pakistan Fertility Survey. Eds. I. Alam and B. Dinesen. Voorburg, Netherlands: International Statistical Institute. Pp. 149-162.

Shelton, James D., Lois Bradshaw, Babar Hussein, Zeba Zubair, Tony Drexler, and Mark Reade McKenna. 1999. "Putting unmet need to the test: Community-based distribution of family planning in Pakistan." International Family Planning Perspectives 25(4): 191-195.

Sirageldin, Ismail, Douglas Norris, and J. Gilbert Hardee. 1976. "Family planning in Pakistan: An analysis of some factors constraining use." Studies in Family Planning 7(5): 144-154.

Stash, Sharon. 1999. "Explanations of unmet need for contraception in Chitwan, Nepal." Studies in Family Planning 30(4): 267-287.

Thompson, Elizabeth. 1990. "Fertility desires and fertility: Hers, his and theirs." Demography 27 (4): 579-588.

Tsui, Amy Ong. 1996. "Family Planning Programs in Asia: Approaching a Half-Century of Effort." Asia-Pacific Population Research Reports No. 8. Honolulu: East-West Center, Program on Population. 
United Nations. 1993. Women's Status and Fertility in Pakistan: Recent Evidence. New York: United Nations, Department for Economic and Social Information and Policy Analysis.

Viswanathan, Hema, Sona Godfrey, and Nancy Yinger. 1998. Reaching Women: A Study of Unmet Need in Uttar Pradesh, India. Washington, DC: International Center for Research on Women.

Westoff, Charles F. and Akinrinola Bankole. 1995. "Unmet Need: 1990-1994. Demographic and Health Surveys Comparative Studies No. 16. Calverton, MD: Macro International.

- 2000. "Trends in the demand for family limitation in developing countries." International Family Planning Perspectives 26(2): 56-62.

Winkvist, A. and H.Z. Akhtar. 2000. "God should give daughters to rich families only: Attitudes towards childbearing among low-income women in Punjab, Pakistan." Social Science and Medicine 51(1): 73-81.

Yinger, Nancy V. 1998. Unmet Need for Family Planning: Reflecting Women's Perceptions. Washington, DC: International Center for Research on Women. 


\section{POLICY RESEARCH DIVISION WORKING PAPERS}

Recent Back Issues

1999

*120 John Bongaarts, “The fertility impact of changes in the timing of childbearing in the developing world."

*121 James F. Phillips, Wendy L. Greene, and Elizabeth F. Jackson, "Lessons from community-based distribution of family planning in Africa."

122 Mark R. Montgomery, "Mortality decline and the demographic response: Toward a new agenda."

*123 Mark R. Montgomery, Mary ArendsKuenning, and Cem Mete, "The quantity-quality transition in Asia."

124 Barbara S. Mensch, Wesley H. Clark, Cynthia B. Lloyd, and Annabel S. Erulkar, "Premarital sex and school dropout in Kenya: Can schools make a difference?"

125 John Bongaarts and Rodolfo A. Bulatao, "Completing the demographic transition."

126 Geoffrey McNicoll, "Population weights in the international order."
127 Cynthia B. Lloyd, Carol E. Kaufman, and Paul Hewett, "The spread of primary schooling in sub-Saharan Africa: Implications for fertility change."

128 John B. Casterline, "The onset and pace of fertility transition: National patterns in the second half of the twentieth century."

129 Mark R. Montgomery, Michele Gragnolati, Kathleen Burke, and Edmundo Paredes, "Measuring living standards with proxy variables."

130 Bamikale Feyisetan and John B. Casterline, "Fertility preferences and contraceptive change in developing countries."

131 Martin Brockerhoff, "Urban growth in developing countries: A review of projections and predictions."

132 Omaima El-Gibaly, Barbara Ibrahim, Barbara S. Mensch, and Wesley H. Clark, "The decline of female circumcision in Egypt: Evidence and interpretation."

* No longer available 
133 Mary Arends-Kuenning and Sajeda Amin, "The effects of schooling incentive programs on household resource allocation in Bangladesh."

134 John Bongaarts and Charles F. Westoff, "The potential role of contraception in reducing abortion."

135 John B. Casterline and Steven W. Sinding, "Unmet need for family planning in developing countries and implications for population policy."

*136 Carol E. Kaufman, Thea de Wet, and Jonathan Stadler, "Adolescent pregnancy and parenthood in South Africa."

137 Valerie L. Durrant and Zeba A. Sathar, "Greater investments in children through women's empowerment: A key to demographic change in Pakistan?"

138 Sajeda Amin, Alaka Malwade Basu, and Rob Stephenson, "Spatial variation in contraceptive use in Bangladesh: Looking beyond the borders."
139 Geoffrey McNicoll, "Managing population-environment systems: Problems of institutional design."

140 Barbara S. Mensch, Barbara L. Ibrahim, Susan M. Lee, and Omaima El-Gibaly, "Socialization to gender roles and marriage among Egyptian adolescents."

141 John Bongaarts and Elof Johansson, "Future trends in contraception in the developing world: Prevalence and method mix."

142 Alaka Malwade Basu and SajedaAmin, "Some preconditions for fertility decline in Bengal: History, language identity, and an openness to innovations."

143 Zeba Sathar, Cynthia B. Lloyd, Cem Mete, and Minhaj ul Haque, "Schooling opportunities for girls as a stimulus for fertility change in rural Pakistan.”

2001

144 John Bongaarts, "Household size and composition in the developing world."

145 John B. Casterline, Zeba A. Sathar, and Minhaj ul Haque, "Obstacles to contraceptive use in Pakistan: A study in Punjab." 